\title{
Ultrasonic Investigations of Molecular Interaction in Binary Mixtures of Cyclohexanone with Isomers of Butanol
}

\author{
Sk. Md Nayeem, ${ }^{1}$ M. Kondaiah, ${ }^{2}$ K. Sreekanth, ${ }^{3}$ and D. Krishna Rao ${ }^{4}$ \\ ${ }^{1}$ Department of Physics, KRK Government Degree College, Addanki 523 201, India \\ ${ }^{2}$ Department of Physics, NM Government Degree College, Jogipet, Medak District, Telangana, India \\ ${ }^{3}$ Department of Physics, PBN College, Nidubrolu, Guntur District, India \\ ${ }^{4}$ Department of Physics, Acharya Nagarjuna University, Nagarjuna Nagar 522 510, India
}

Correspondence should be addressed to D. Krishna Rao; krdhanekula@yahoo.co.in

Received 11 August 2014; Revised 21 October 2014; Accepted 3 November 2014; Published 18 December 2014

Academic Editor: Parsotam H. Parsania

Copyright (C) 2014 Sk. Md Nayeem et al. This is an open access article distributed under the Creative Commons Attribution License, which permits unrestricted use, distribution, and reproduction in any medium, provided the original work is properly cited.

\begin{abstract}
Ultrasonic speed, $u$, and density, $\rho$, have been measured in binary liquid mixtures of cyclohexanone with the isomers of butanol ( $n$-butanol, sec-butanol, and tert-butanol) at $308.15 \mathrm{~K}$ over the entire range of composition. Molar volume $\left(V_{m}\right)$, adiabatic compressibility $\left(k_{s}\right)$, intermolecular free length $\left(L_{f}\right)$, acoustic impedance $(z)$, and their excess/deviation along with $\Delta u$ have been calculated from the experimental data. These values have been fitted to Redlich-Kister type polynomial equation. Positive values of $V_{m}^{E}, \Delta k_{s}, L_{f}^{E}$ and negative values of $z^{E}, \Delta u$ have been observed for all the liquid mixtures indicating the existence of weak interactions between components. Rupture of H-bond or reduction in H-bond strength of isomers of butanol or breaking of the structure of one or both of the components in a solution causes the existence of dispersions in the present investigated binary mixtures. The data obtained from $\bar{V}_{m, 1}, \bar{V}_{m, 2}$, and excess partial molar volumes $\bar{V}_{m, 1}^{E}, \bar{V}_{m, 2}^{E}$, reflects the inferences drawn from $V_{m}^{E}$. Furthermore, FTIR spectra support the conclusions drawn from excess/deviation properties. The measured values of ultrasonic speed for all the investigated mixtures have been compared with the theoretically estimated values using empirical relations such as, Nomoto, Van Dael and Vangeels, Impedance and Rao specific sound speed.
\end{abstract}

\section{Introduction}

Ultrasonic measurements are very useful in chemical and food processing, pharmaceuticals, material testing, and underwater ranging and cleaning and are also commonly employed in mechanical machinery of materials [1], preparation of colloids or emulsions, the pregermination of seeds, imaging of biological tissues [2], activation energy of metabolic process [3], formation and destruction of azeotropes in petrochemical industries [4], and nondestructive testing (NDT).

Alcohols are self-associated organic liquids, used for the synthesis of other organic compounds. They are also widely used as coupling and dispersing agents in the chemical, pharmaceutical, and household industries and as carrier and extraction solvents for natural products. Cyclohexanone and its derivatives are used for the synthesis of pharmaceuticals, dyes, herbicides, pesticides, plasticizers, and rubber chemicals. Ketones are a class of an organic compound that contains a carbonyl group and two aliphatic or aromatic substituents containing the chemical formula $\mathrm{RCOR}^{1}$ (general chemical formula of Ketones). The chemical reactivity of the carbonyl group plays vital role in chemical reactions and is influenced considerably by steric effects. The greater electronegativity of $\mathrm{O}^{-}$and high dipole moment value make Cyclohexanone polar. Scheme 1 illustrates this polarity. Further the presence of oxygen with its nonbonding electron pairs makes cyclohexanone $\mathrm{H}$-bond acceptors. Thus a study on thermophysical properties data of binary liquid mixtures containing ketones has attracted considerable interest in the literature [5-9].

Literature survey reveals that Tsierkezos et al. [10] studied molecular interactions in cyclohexanone with methanol, ethanol, 1-propanol, 1-butanol, and 1-pentanol at $293.15 \mathrm{~K}$ and Sri Lakshmi et al. [11] studied molecular interactions in 


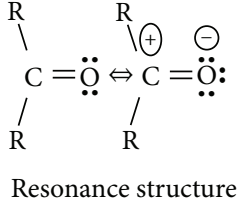

SCHEME 1

cyclohexanone with $n$-heptanol, $n$-octanol, and isooctanol at temperatures $303.15,308.15,313.15$, and $318.15 \mathrm{~K}$ over the entire range of composition. Keeping these important aspects in mind, the present study deals with ultrasonic and thermodynamic study of cyclohexanone $(\mathrm{CH})$ with the isomers of butanol ( $n$-butanol, sec-butanol, and tert-butanol) at $308.15 \mathrm{~K}$. The liquids under investigation have been chosen on the basis of their multifold applications.

\section{Experimental Section}

High purity analytical reagent (AR) grade compounds of cyclohexanone (mass fraction purity > 99\%) and $n$-butanol, sec-butanol, and tert-butanol (mass fraction purity > 99.5\%) obtained from S D Fine Chemicals are used in the present study. The chemicals are further purified by standard methods mentioned in $[12,13]$. The weighing of solutions has been made using METTLER TOLEDO (Switzerland make) ABB5S/FACT digital balance with an accuracy of $\pm 0.01 \mathrm{mg}$. The uncertainty in the mole fraction is $10^{-4}$. The ultrasonic speeds of pure liquids and liquid mixtures have been measured using an ultrasonic interferometer (Mittal type, Model F-82) working at $2 \mathrm{MHz}$ fixed frequency with an accuracy of $\pm 0.2 \%$. The temperature of liquid sample in the interferometer cell is maintained constant by circulating water pumped from constant temperature water bath. In the present study the constant temperature water bath (digital electronic) supplied by Concord Instruments Co. Ltd., Chennai (RAAGA type), has been used. The instrument can maintain temperature to $\pm 0.01 \mathrm{~K}$ as per its specifications.

Densities of pure liquids and their mixtures have been determined by using a $5 \mathrm{~cm}^{3}$ two-stem double-walled Parker $\&$ Parker type pycnometer [15]. This pycnometer is calibrated with triply distilled water. The pycnometer filled with air bubble free experimental liquids was kept in a transparent walled constant temperature bath for 20 to $30 \mathrm{~min}$ to attain thermal equilibrium. The positions of the liquid levels in the two arms are recorded with the help of traveling microscope. At least three to four measurements are performed, from which an average value of density of the experimental liquid is determined. The estimated accuracy in the density measurement is 3 in $10^{5}$ parts. The ultrasonic speeds, $u$, and densities, $\rho$, measured at $308.15 \mathrm{~K}$ for the pure liquids used in this investigation are compiled in Table 1 together with the literature data $[11,14]$ available. These results are in good agreement with the reported data.

\section{Theory}

Thermodynamic and acoustical parameters such as molar volume $\left(V_{m}\right)$, adiabatic compressibility $\left(k_{s}\right)$, intermolecular
TABLE 1: Comparison of experimental values of density, $\rho$, and ultrasonic speed, $u$, of pure liquids with the corresponding literature values at $308.15 \mathrm{~K}$.

\begin{tabular}{lcccc}
\hline \multirow{2}{*}{ Liquid } & \multicolumn{2}{c}{$\rho /\left(\mathrm{kg} \mathrm{m}^{-3}\right)$} & \multicolumn{2}{c}{$u /\left(\mathrm{m} \mathrm{s}^{-1}\right)$} \\
& $\begin{array}{c}\text { Present } \\
\text { work }\end{array}$ & Literature & $\begin{array}{c}\text { Present } \\
\text { work }\end{array}$ & Literature \\
\hline Cyclohexanone & 939.60 & $939.6[11]$ & 1362.00 & $1362.0[11]$ \\
$n$-Butanol & 796.50 & $796.5[14]$ & 1209.30 & $1209.3[14]$ \\
sec-Butanol & 793.20 & $793.2[14]$ & 1174.80 & $1174.8[14]$ \\
tert-Butanol & 768.40 & $768.3[14]$ & 1086.00 & $1086.0[14]$ \\
\hline
\end{tabular}

free length $\left(L_{f}\right)$, and acoustic impedance $(z)$ are evaluated using the relations given below:

$$
V_{m}=\frac{M_{\mathrm{eff}}}{\rho},
$$

where $M_{\text {eff }}$ is given by $M_{\text {eff }}=\left(x_{1} M_{1}+x_{2} M_{2}\right)$, where $M_{1}$ and $M_{2}$ are the molar masses of pure components, and $\rho$ is the density of the liquid mixture.

The speed of sound $(u)$ and the density of the medium $(\rho)$ are related by using Newton and Laplace equation as

$$
\begin{gathered}
k_{s}=\frac{1}{\rho u^{2}}, \\
L_{f}=K k_{s}^{1 / 2} .
\end{gathered}
$$

Here $K$ is the temperature dependent constant which is equal to $K=(93.875+0.375 T) \times 10^{-8}$ where $T$ is absolute temperature. Consider

$$
z=u \rho \text {. }
$$

In order to understand the nature of the molecular interactions between the components of the liquid mixtures, it is of interest to discuss the same in terms of excess parameters rather than actual values. Nonideal liquid mixtures show considerable deviation from linearity in their concentrations and this has been interpreted to arise from the presence of strong or weak interactions. The difference between the properties of the real mixtures $\left(Y_{\text {real }}\right)$ and those corresponding to ideal mixture $\left(Y_{\text {ideal }}=\sum x_{i} Y_{i}\right)$ values, namely, excess properties $\left(Y^{E}\right)$, such as excess molar volume $\left(V_{m}^{E}\right)$, free length $\left(L_{f}^{E}\right)$, acoustic impedance $\left(z^{E}\right)$, and deviations in ultrasonic speed $(\Delta u)$, is computed by the relation

$$
Y^{E}=Y_{\text {real }}-\sum x_{i} Y_{i}
$$

where $Y^{E}=V_{m}^{E}, L_{f}^{E}, z^{E}$ and $\Delta u ; x_{i}$ is the mole fraction and $Y_{i}$ is the value of the property of the $i$ th component liquid of mixture.

The deviation in adiabatic compressibility $\left(\Delta k_{s}\right)$ has been calculated from the equation

$$
\Delta k_{s}=k_{s}-\left(\Phi_{1} k_{s 1}+\Phi_{2} k_{s 2}\right)
$$


where $\Phi_{1}, \Phi_{2}$, and $k_{s 1}, k_{s 2}$ are the volume fractions and adiabatic compressibilities of components 1 and 2, respectively. Since $k_{s}$ is not additive on mole fraction but is additive on volume fraction, such values are calculated using volume fraction $(\Phi)$ :

$$
\Phi_{i}=\frac{x_{i} V_{i}}{\sum x_{i} V_{i}} .
$$

The experimentally measured values of ultrasonic speed $(u)$ and density $(\rho)$ and calculated properties of molar volume $\left(V_{m}\right)$, adiabatic compressibility $\left(k_{s}\right)$, intermolecular free length $\left(L_{f}\right)$, and acoustic impedance $(z)$ and excess/deviation thermodynamic properties $V_{m}^{E}, L_{f}^{E}, z^{E}, \Delta u$, and $\Delta k_{s}$ are presented in Table 2 for all binary systems over the entire composition range of $\mathrm{CH}$.

The excess/deviation properties have been fitted to a Redlich-Kister type polynomial equation [16]

$$
Y^{E}=x_{1} x_{2} \sum_{i=0}^{n} A_{i}\left(x_{2}-x_{1}\right)^{i},
$$

where $Y^{E}=V_{m}^{E}, L_{f}^{E}, z^{E}, \Delta u$ and $\Delta k_{s} ; x_{1}$ is the mole fraction of the solute.

The values of $\Delta k_{s}$ have been fitted to Redlich-Kister type polynomial with volume fraction instead of mole fraction in the above polynomial and $A_{i}$ are the adjustable parameters of the function and are determined using the least square method. In the present investigation " $i$ " values are taken from 0 to 4 . The corresponding standard deviation $\sigma\left(Y^{E}\right)$ was calculated using the expression

$$
\sigma\left(Y^{E}\right)=\left[\frac{\sum\left(Y_{\text {exp }}^{E}-Y_{\text {cal }}^{E}\right)^{2}}{(m-n)}\right]^{1 / 2},
$$

where " $m$ " is the total number of experimental points and " $n$ " is the number of coefficients in (7). The calculated values of the coefficients $A_{i}$ along with the standard deviations $(\sigma)$ have been presented in Table 3 .

\section{Results and Discussion}

Figure 1 represents the variation of excess molar volume $\left(V_{m}^{E}\right)$ with mole fraction of $\mathrm{CH}$. The sign of $V_{m}^{E}$ depends upon the contraction and expansion of volume of the liquids due to mixing. The factors that are mainly responsible for the expansion of molar volume, that is, positive values of $V_{m}^{E}$, are the following: (i) breaking of the structure of one or both of the components in a solution, that is, the loss of dipolar association between the molecules (dispersion forces); (ii) $\mathrm{H}$ bond rupture and stretching of self-associated molecules (like alcohols); (iii) the geometry of molecular structures which does not favour the fitting of molecules of one component into void space of another molecule; (iv) steric hindrance of the molecules. The negative values of $V_{m}^{E}$ are due to the (i) association of molecules through the formation of hydrogen bond, that is, strong specific interactions, and (ii) accommodation of molecules because of large differences in their

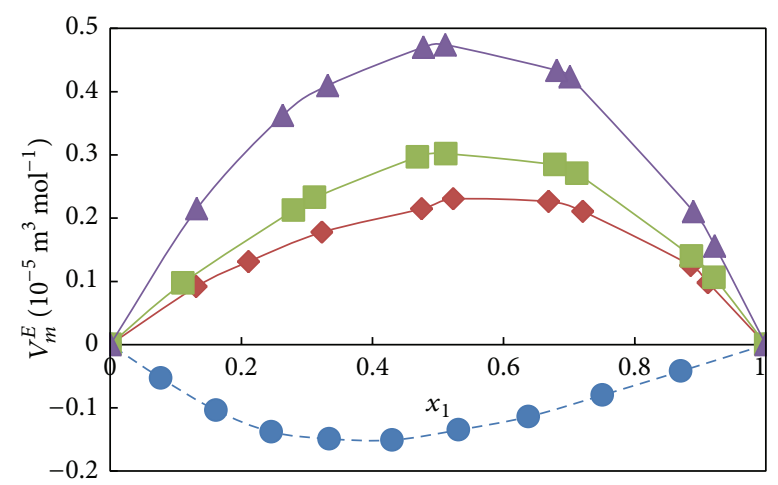

FIGURE 1: Variation of excess molar volume, $V_{m}^{E}$, with mole fraction, $x_{1}$, of cyclohexanone in $(\diamond), n$-butanol/(ם), sec-butanol $/(\boldsymbol{\Delta})$, and tert-butanol at $308.15 \mathrm{~K}$ and Tsierkezos et al. [10] for cyclohexanone + 1-butanol (dotted lines) at $293.15 \mathrm{~K}$.

molar volumes. In other words, $V_{m}^{E}$ arises due to the result of physical, chemical, and structural contributions. Physical interactions involving mainly nonspecific interactions such as dispersion or weak forces (breaking of the liquid order on mixing, i.e., loss of dipolar association between the molecules) contribute to positive $V_{m}^{E}$. The chemical or specific interactions such as complex formation and hydrogen bond formation between constituent molecules contribute to negative $V_{m}^{E}$. The structural effects arise from interstitial accommodation due to the difference in the molar volumes and free volumes between the liquid components on mixing contributing to negative $V_{m}^{E}$ [17]. The variation of $V_{m}^{E}$ is found to be positive over the entire composition range in the present investigation which indicates that weak forces exist. Sri Lakshmi et al. [11] reported similar results in $\mathrm{CH}$ with $n$-heptanol, $n$-octanol, and iso-octanol at temperatures of 303.15, 308.15, 313.15 , and $318.15 \mathrm{~K}$. The $V_{m}^{E}$ data obtained by Tsierkezos et al. [10] for CH + 1-butanol binary system are negative at $293.15 \mathrm{~K}$ whereas in our investigations they are found to be positive when performed at $308.15 \mathrm{~K}$. Such behaviour may arise due to the fact that as temperature increases the effective collision between the component molecules increases. Thus larger number of free dipoles of component molecules may be available due to declusttering of molecules in the pure state.

The nature of interaction in binary liquids can be analysed by knowing their chemical and physical properties (physicochemical properties). Generally, butanols are associated through the hydrogen bonding as shown below and in the pure state, they exhibit equilibrium between the monomer and multimer species. Also, they can be associated with any other groups having some degree of polar attractions. As discussed earlier, butanol exhibits strong intermolecular interactions (H-bond). Alcohol size, chain length, and physical properties (boiling point, density, hydrophobic property, viscosity, insolubility, and refractive index) are important parameters that must be taken into account to explain the behaviour of the interactions (Scheme 2).

$\mathrm{CH}$ is a polar molecule because of the presence of carbonyl group $(\mathrm{C}=\mathrm{O})$; this is due to the fact that oxygen is more electronegative $\left(\mathrm{O}^{-}\right)$than carbon $\left(\mathrm{C}^{+}\right)$. Thus they 


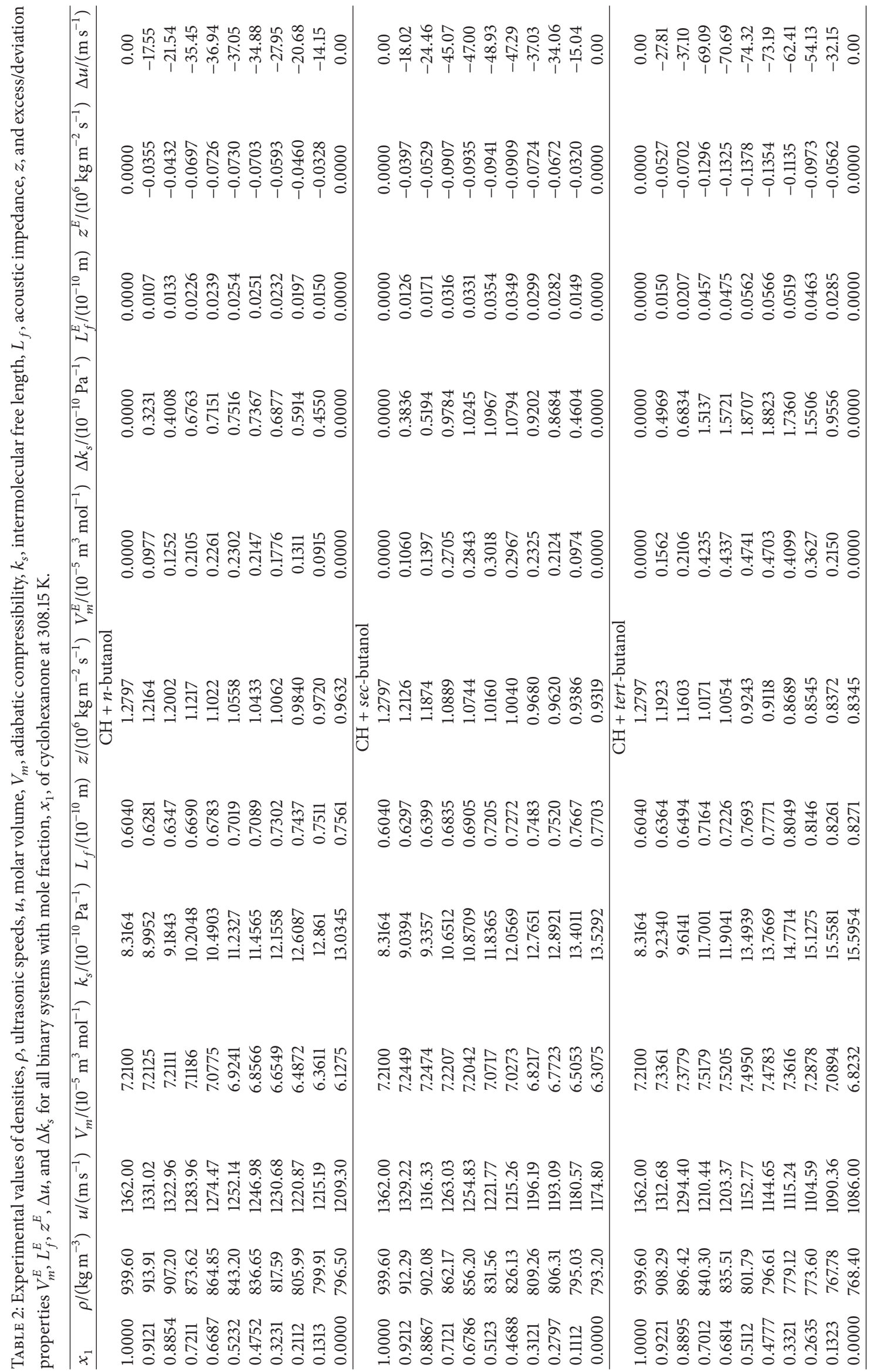


TABLE 3: Coefficients $A_{i}$ of Redlich-Kister type polynomial equation (7) and the corresponding standard deviations, $\sigma$, of all the systems at $308.15 \mathrm{~K}$.

\begin{tabular}{|c|c|c|c|c|c|c|}
\hline & $A_{0}$ & $A_{1}$ & $A_{2}$ & $A_{3}$ & $A_{4}$ & $\sigma$ \\
\hline \multicolumn{7}{|c|}{$\mathrm{CH}+n$-butanol } \\
\hline$V_{m}^{E} /\left(10^{-5} \mathrm{~m}^{3} \mathrm{~mol}^{-1}\right)$ & 24.7625 & -5.7880 & 3.6945 & -3.1381 & -0.8351 & 0.0019 \\
\hline$\Delta k_{s} /\left(10^{-10} \mathrm{~Pa}^{-1}\right)$ & 0.0183 & -0.0020 & 0.0075 & 0.0029 & -0.0004 & 0.0091 \\
\hline$L_{f}^{E} /\left(10^{-10} \mathrm{~m}\right)$ & 0.8201 & -0.1460 & 0.2529 & 0.0638 & 0.1066 & 0.0009 \\
\hline$z^{E} /\left(10^{6} \mathrm{~kg} \mathrm{~m}^{-2} \mathrm{~s}^{-1}\right)$ & -0.2875 & 0.0836 & -0.1081 & 0.0006 & -0.0202 & 0.0002 \\
\hline$\Delta u /\left(\mathrm{ms}^{-1}\right)$ & -1.40 & 0.58 & -0.31 & -0.03 & -0.18 & 0.0024 \\
\hline \multicolumn{7}{|c|}{$\mathrm{CH}+$ sec-butanol } \\
\hline$V_{m}^{E} /\left(10^{-5} \mathrm{~m}^{3} \mathrm{~mol}^{-1}\right)$ & 27.5896 & -9.594 & 4.2809 & -2.2460 & -0.7780 & 0.0018 \\
\hline$\Delta k_{s} /\left(10^{-10} \mathrm{~Pa}^{-1}\right)$ & 0.0267 & -0.001 & 0.0001 & 0.0033 & 0.0034 & 0.0001 \\
\hline$L_{f}^{E} /\left(10^{-10} \mathrm{~m}\right)$ & 1.1507 & -0.1810 & 0.0576 & 0.1082 & 0.0684 & 0.0011 \\
\hline$z^{E} /\left(10^{6} \mathrm{~kg} \mathrm{~m}^{-2} \mathrm{~s}^{-1}\right)$ & -0.3733 & 0.1252 & -0.0791 & 0.0092 & -0.0110 & 0.0001 \\
\hline$\Delta u /\left(\mathrm{ms}^{-1}\right)$ & -1.94 & 0.59 & -0.04 & -0.01 & -0.04 & 0.0006 \\
\hline \multicolumn{7}{|c|}{$\mathrm{CH}+$ tert -butanol } \\
\hline$V_{m}^{E} /\left(10^{-5} \mathrm{~m}^{3} \mathrm{~mol}^{-1}\right)$ & 36.4535 & -12.3900 & -0.6780 & 0.1003 & -0.2750 & 0.0009 \\
\hline$\Delta k_{s} /\left(10^{-10} \mathrm{~Pa}^{-1}\right)$ & 0.0428 & 0.0120 & 0.0024 & 0.0019 & 0.0011 & 0.0001 \\
\hline$L_{f}^{E} /\left(10^{-10} \mathrm{~m}\right)$ & 1.8117 & 0.1253 & 0.1393 & 0.0862 & -0.0290 & 0.0006 \\
\hline$z^{E} /\left(10^{6} \mathrm{~kg} \mathrm{~m}^{-2} \mathrm{~s}^{-1}\right)$ & -0.5484 & 0.1374 & -0.0850 & 0.0123 & -0.0032 & 0.0001 \\
\hline$\Delta u /\left(\mathrm{ms}^{-1}\right)$ & -2.96 & 0.62 & -0.54 & 0.01 & -0.01 & 0.0001 \\
\hline
\end{tabular}

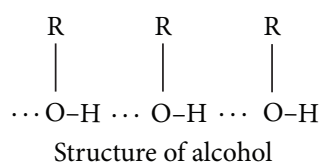

SCHEME 2

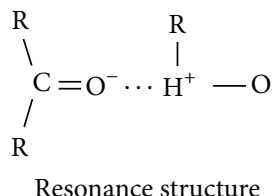

SCHEME 3

cause strong dipole-dipole interactions in chemical reactions. Moreover $\mathrm{CH}$ lacks hydroxyl groups, so it is incapable of creating intermolecular hydrogen bonds. In $\mathrm{CH}+$ isomers of butanol binary systems, the negatively charged oxygen $\left(\mathrm{O}^{-}\right)$in $\mathrm{CH}$ tries to drag the positively charged $\mathrm{H}^{+}$which were bounded in very strong intermolecular interactions of butanol (Scheme 3). An equilibrium stage is reached where rupturing of hydrogen bond or reduction in $\mathrm{H}$-bond strength of butanol or breaking of the structure of one or both of the components in a solution, that is, the loss of dipolar association between the molecules (dispersion forces) [18], will be favourable leading to weak interactions. This causes increase in volume of binary liquid and explains the observed positive values $V_{m}^{E}$ in the systems.

Kiyohara and Benson [19] have suggested that $\Delta k_{s}$ is the resultant of several opposing effects. Negative values of $\Delta k_{s}$ contribute to charge transfer, dipole-induced dipole and

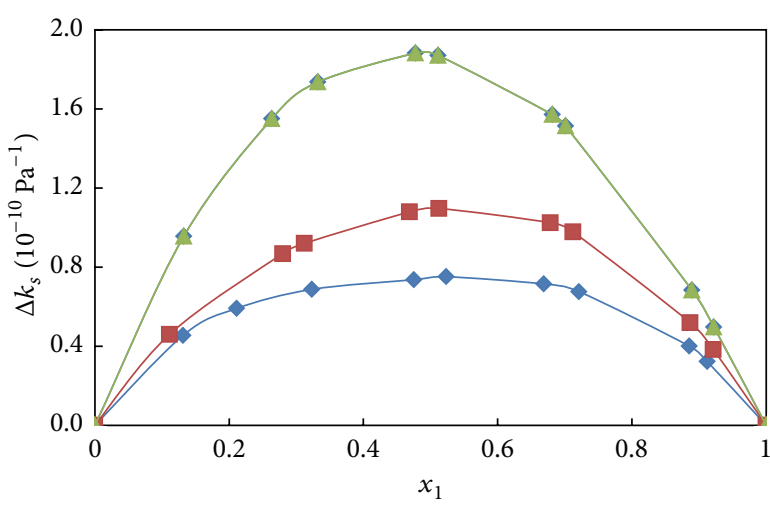

FIGURE 2: Variation of deviation in adiabatic compressibility, $\Delta k_{s}$,

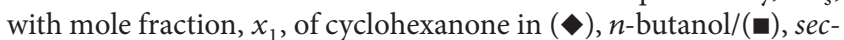
butanol/( $\mathbf{\Lambda})$, and tert-butanol at $308.15 \mathrm{~K}$.

dipole-dipole interactions, interstitial accommodation, and breaking up of the alcohol structures leads to positive values of $\Delta k_{s}$. From Figure 2, the observed positive values of $\Delta k_{s}$ for binary mixtures of $\mathrm{CH}$ with $n$-butanol, sec-butanol, and tertbutanol are due to declustering of alcohols in the presence of $\mathrm{CH}$. The positive deviation in $\Delta k_{s}$ for the binary systems follows the order $\mathrm{CH}+$, tert-butanol $>$ sec-butanol $>n$-butanol. Figure 3 represents the variation of $L_{f}^{E}$ with mole fraction $\left(x_{1}\right)$ of $\mathrm{CH}$. The observed values of $L_{f}^{E}$ are positive. According to Fort and Moore [20], positive $L_{f}^{E}$ should be attributed to the dispersive forces. As mentioned earlier, positive values of $\Delta k_{s}$ and $L_{f}^{E}$ are mainly attributed to weak forces between the component molecules in the mixture [21]. 


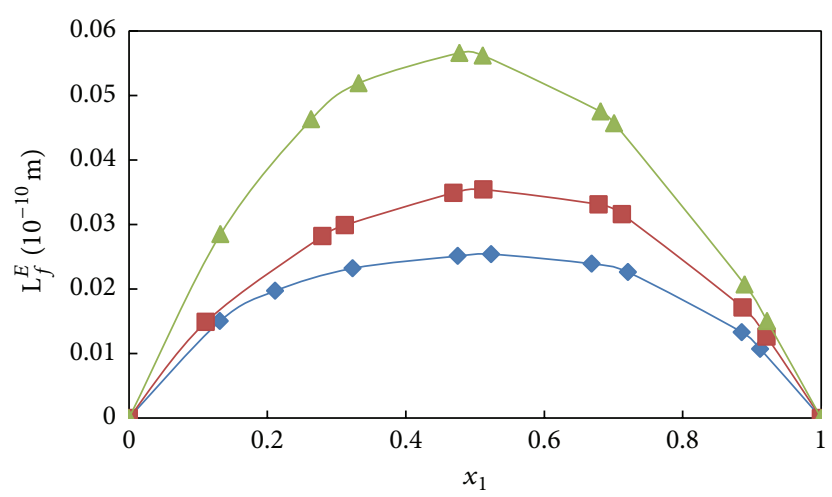

Figure 3: Variation of excess free length, $L_{f}^{E}$, with mole fraction, $x_{1}$, of cyclohexanone in $(\diamond), n$-butanol/( $\bullet), \sec$-butanol/( $\mathbf{\Delta})$, and tertbutanol at $308.15 \mathrm{~K}$.

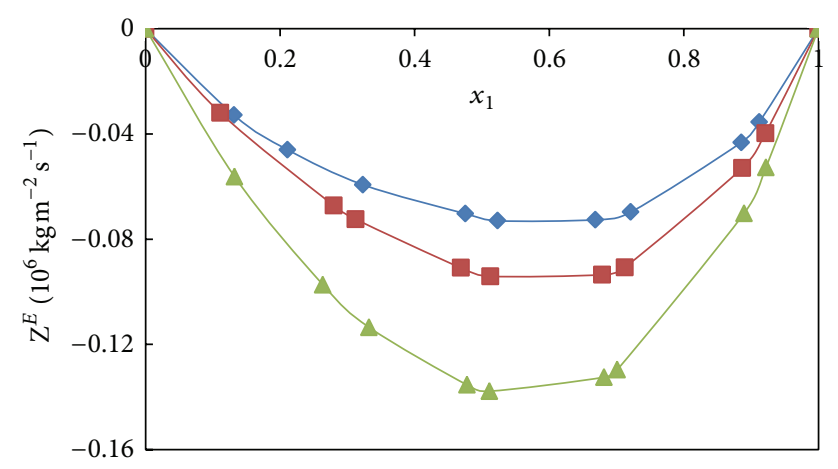

FIgURE 4: Variation of excess acoustic impedance, $z^{E}$, with mole fraction, $x_{1}$, of cyclohexanone in $(\bullet), n$-butanol/( $(\boldsymbol{\square})$, secbutanol $/(\mathbf{\Lambda})$, and tert-butanol at $308.15 \mathrm{~K}$.

The variations of excess acoustic impedance $\left(z^{E}\right)$ and deviation in ultrasonic speed $(\Delta u)$ have been presented in Figures 4 and 5, respectively. From Figure 4 , it has been observed that the values of $z^{E}$ are negative over the entire mole fraction range indicating the decreasing strength of interactions between component molecules of the mixture. According to Gowrisankar et al. [22], the negative values for $\Delta u$ indicate the decrease in the strength of interaction between the molecules and the negative deviations in $\Delta u$ from linear dependence suggest the presence of weak interaction between the component molecules. These deviation/ excess properties further support the conclusions drawn from $V_{m}^{E}, L_{f}^{E}$, and $\Delta k_{s}$.

The existing molecular interactions in the systems are well reflected in the properties of partial molar volumes. The partial molar volumes $\bar{V}_{m, 1}$ of component $1(\mathrm{CH})$ and $\bar{V}_{m, 2}$ of component 2 (isomers of butanol) in the mixtures over the entire composition range have been calculated by using the following relations:

$$
\bar{V}_{m, 1}=V_{m}^{E}+V_{1}^{*}+x_{2}\left(\frac{\partial V_{m}^{E}}{\partial x}\right)_{T, P}
$$

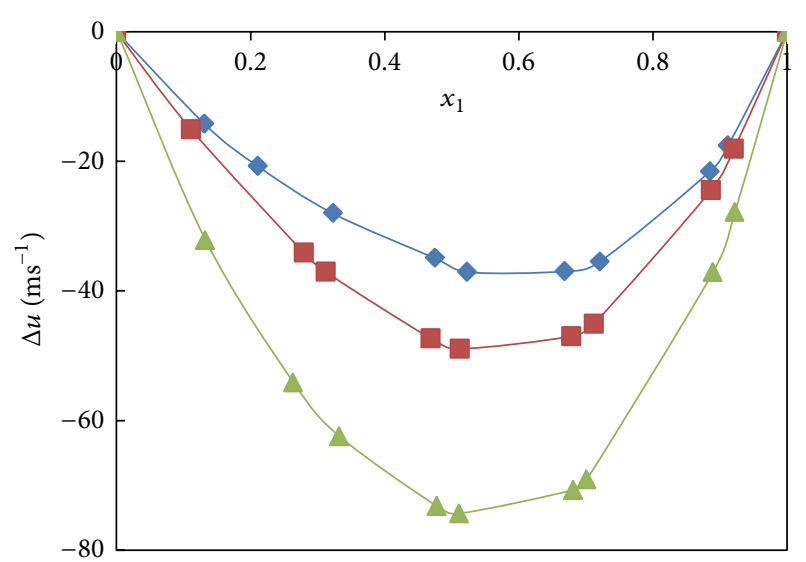

FIGURE 5: Variation of deviation in ultrasonic speed, $\Delta u$, with mole fraction, $x_{1}$, of cyclohexanone in $(\bullet), n$-butanol/( $\left.\mathbf{\square}\right)$, secbutanol/( $\mathbf{\Delta})$, and tert-butanol at $308.15 \mathrm{~K}$.

$$
\bar{V}_{m, 2}=V_{m}^{E}+V_{2}^{*}+x_{1}\left(\frac{\partial V_{m}^{E}}{\partial x}\right)_{T, P},
$$

where $V_{1}^{*}$ and $V_{2}^{*}$ are the molar volumes of the pure components of $\mathrm{CH}$ and butanols, respectively. The derivates in the above equations are obtained by differentiating RedlichKister equation (7) which leads to the following equations for $\bar{V}_{m, 1}$ and $\bar{V}_{m, 2}$ :

$$
\begin{aligned}
& \bar{V}_{m, 1}=V_{1}^{*}+x_{2}^{2} \sum_{i=0}^{j} A_{i}\left(x_{2}-x_{1}\right)^{i}-2 x_{1} x_{2}^{2} \sum_{i=1}^{j} A_{i}\left(x_{2}-x_{1}\right)^{i-1}, \\
& \bar{V}_{m, 2}=V_{2}^{*}+x_{1}^{2} \sum_{i=0}^{j} A_{i}\left(x_{2}-x_{1}\right)^{i}+2 x_{2} x_{1}^{2} \sum_{i=1}^{j} A_{i}\left(x_{2}-x_{1}\right)^{i-1} ;
\end{aligned}
$$

using the above equations $\bar{V}_{m, 1}^{E}, \bar{V}_{m, 2}^{E}$ have been calculated using

$$
\begin{aligned}
& \bar{V}_{m, 1}^{E}=\bar{V}_{m, 1}-V_{1}^{*}, \\
& \bar{V}_{m, 2}^{E}=\bar{V}_{m, 2}-V_{2}^{*} .
\end{aligned}
$$

The pertinent values of $\bar{V}_{m, 1}$ and $\bar{V}_{m, 2}$ are furnished in Table 4. From this table, the values of $\bar{V}_{m, 1}$ and $\bar{V}_{m, 2}$ for both the components in the mixtures are greater than their respective molar volumes in the pure state; that is, an expansion of volume takes place on mixing alcohols with ketone. These results also support the observed positive values of $V_{m}^{E}$ in all the binary systems. Figures 6 and 7 represent the variation of excess partial molar volumes of $\bar{V}_{m, 1}^{E}(\mathrm{CH}), \bar{V}_{m, 2}^{E}$ (isomers of butanol) in the binary mixtures. Examination of these figures reveals that dispersion forces exist between the unlike molecules. These figures support the conclusions drawn from $V_{m}^{E}$. The partial molar volumes and excess partial 
TABLe 4: Partial molar volumes of $\mathrm{CH}\left(\bar{V}_{m, 1} / 10^{-5} \mathrm{~m}^{3} \mathrm{~mol}^{-1}\right)$ and butanols $\left(\bar{V}_{m, 2} / 10^{-5} \mathrm{~m}^{3} \mathrm{~mol}^{-1}\right)$ of all the binary systems with mole fraction $\left(x_{1}\right)$ of $\mathrm{CH}$ at $308.15 \mathrm{~K}$.

\begin{tabular}{lcccccccc}
\hline & CH $+n$-butanol & \multicolumn{3}{c}{$\mathrm{CH}+$ sec-butanol } & \multicolumn{3}{c}{ CH + tert-butanol } \\
$x_{1}$ & $\bar{V}_{m, 1}$ & $\bar{V}_{m, 2}$ & $x_{1}$ & $\bar{V}_{m, 1}$ & $\bar{V}_{m, 2}$ & $x_{1}$ & $\bar{V}_{m, 1}$ \\
\hline 1.0000 & 7.210 & 42.676 & 1.0000 & 7.210 & 49.234 & 1.0000 & 7.210 \\
0.9121 & 7.699 & 32.512 & 0.9212 & 7.681 & 38.378 & 0.9221 & 7.606 \\
0.8854 & 7.999 & 30.035 & 0.8867 & 8.130 & 34.445 & 0.8895 & 7.997 & 44.612 \\
0.7211 & 10.600 & 19.303 & 0.7121 & 11.586 & 20.460 & 0.7012 & 12.366 & 23.413 \\
0.6687 & 11.554 & 17.041 & 0.6786 & 12.354 & 18.636 & 0.6814 & 12.989 \\
0.5232 & 14.365 & 12.385 & 0.5123 & 16.219 & 12.221 & 0.5112 & 19.004 & 13.087 \\
0.4752 & 15.378 & 11.198 & 0.4688 & 17.234 & 11.058 & 0.4777 & 20.247 \\
0.3231 & 19.092 & 8.232 & 0.3121 & 20.995 & 8.043 & 0.3321 & 25.389 \\
0.2112 & 22.264 & 6.843 & 0.2797 & 21.794 & 7.619 & 0.2635 & 27.459 \\
0.1313 & 24.403 & 6.314 & 0.1112 & 25.586 & 6.406 & 0.1323 & 3.416 \\
0.0000 & 25.905 & 6.128 & 0.0000 & 26.462 & 6.307 & 0.0000 & 3.211 \\
\hline
\end{tabular}

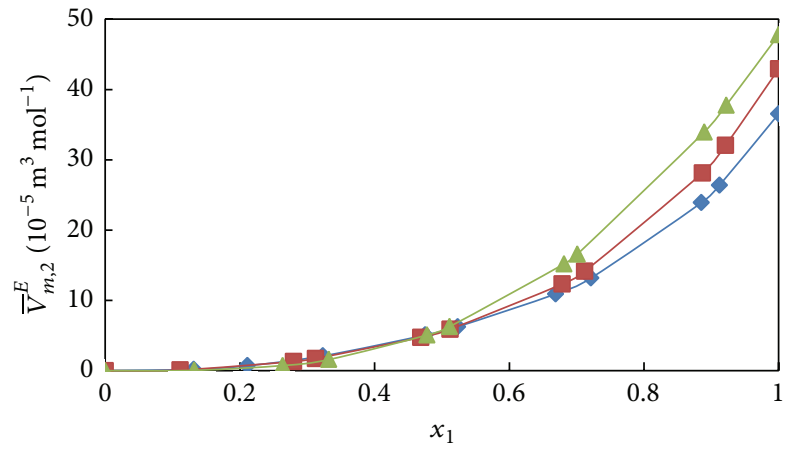

FIGURE 6: Variation of excess partial molar volume, $\bar{V}_{m, 2}^{E}$, with mole fraction, $x_{1}$, of cyclohexanone in $(\bullet), n$-butanol/(ש), secbutanol/(ム), and tert-butanol at $308.15 \mathrm{~K}$.

molar volumes of $\mathrm{CH}$ and isomers of butanols in all the binary liquid mixtures at infinite dilution, $\bar{V}_{m, 1}^{\infty}, \bar{V}_{m, 2}^{\infty}, \bar{V}_{m, 1}^{E, \infty}$, and $\bar{V}_{m, 2}^{E, \infty}$, respectively, were obtained by putting $x=0$ in (10) and $x=1$ in (11). Consider

$$
\begin{aligned}
& \bar{V}_{m, 1}^{E, \infty}=A_{0}+A_{1}+A_{2}+A_{3}+\cdots=\bar{V}_{m, 1}^{\infty}-V_{1}^{*}, \\
& \bar{V}_{m, 2}^{E, \infty}=A_{0}-A_{1}+A_{2}-A_{3}+\cdots=\bar{V}_{m, 2}^{\infty}-V_{2}^{*} .
\end{aligned}
$$

The pertinent values of $\bar{V}_{m, 1}^{\infty}, \bar{V}_{m, 2}^{\infty}, \bar{V}_{m, 1}^{E, \infty}$, and $\bar{V}_{m, 2}^{E, \infty}$ are reported in Table 5. From this table it is seen that these values are positive, from which we conclude that weak interactions exist among the unlike molecules of the liquid mixtures.

FT-IR spectra of pure $\mathrm{CH}$, butanols, and binary mixtures of $\mathrm{CH}$ with butanols at equal concentrations are depicted in Figures 8, 9, and 10. According to Karunakar and Srinivas [23], the intensity of an absorption in the IR spectrum is related to the change in dipole moment that occurs during the vibration. Consequently, vibrations that produce a large change in dipole moment (e.g., $\mathrm{C}=\mathrm{O}$ stretch) result in a more intense absorption than those that result in a relatively modest change in dipole (e.g., $\mathrm{C}=\mathrm{C}$ ). Vibrations that do not result in a change in dipole moment (e.g., a symmetrical

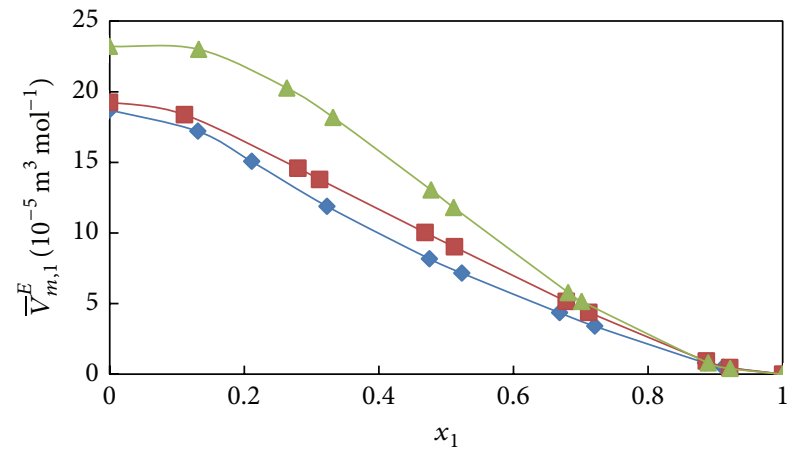

Figure 7: Variation of excess partial molar volume, $\bar{V}_{m, 1}^{E}$, with mole fraction, $x_{1}$, of cyclohexanone in $(\bullet), n$-butanol/( $\left.\mathbf{\square}\right), \mathrm{sec}$ butanol/( $\mathbf{\Delta})$, and tert-butanol at $308.15 \mathrm{~K}$.

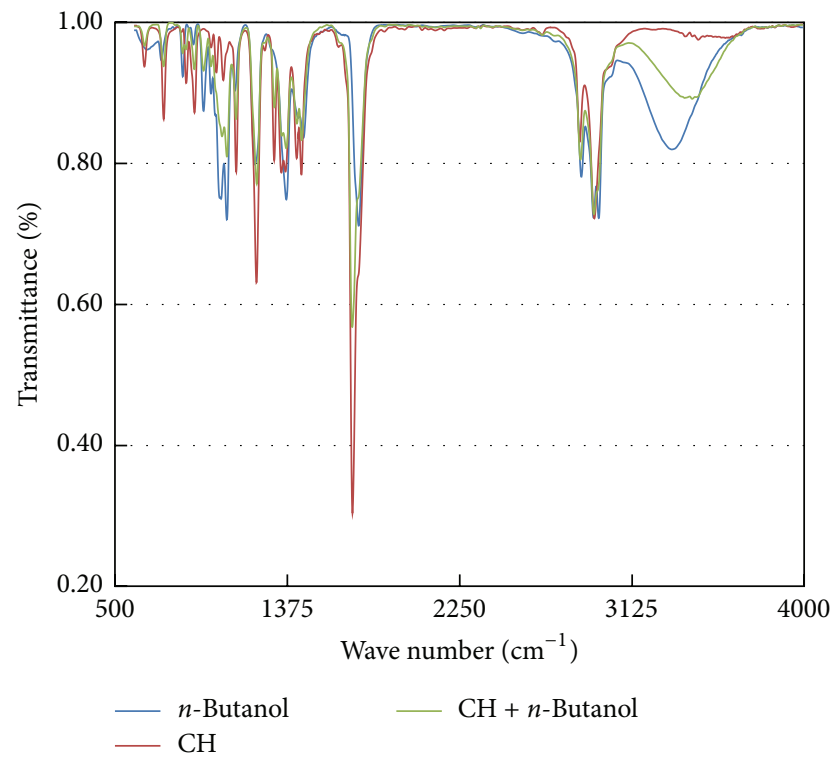

FIGURE 8: Fourier transform infrared spectra of pure cyclohexanone (red), cyclohexanone and $n$-butanol in the ratio 5:5 (green), and pure $n$-butanol (blue). 


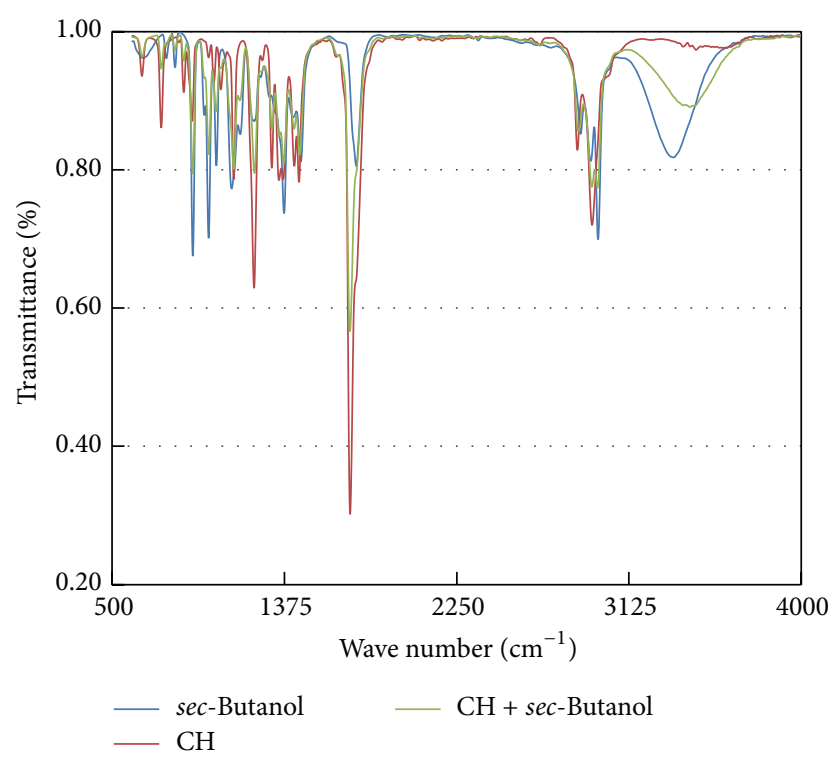

FIGURE 9: Fourier transform infrared spectra of pure cyclohexanone (red), cyclohexanone and sec-butanol in the ratio 5:5 (green), and pure sec-butanol (blue).

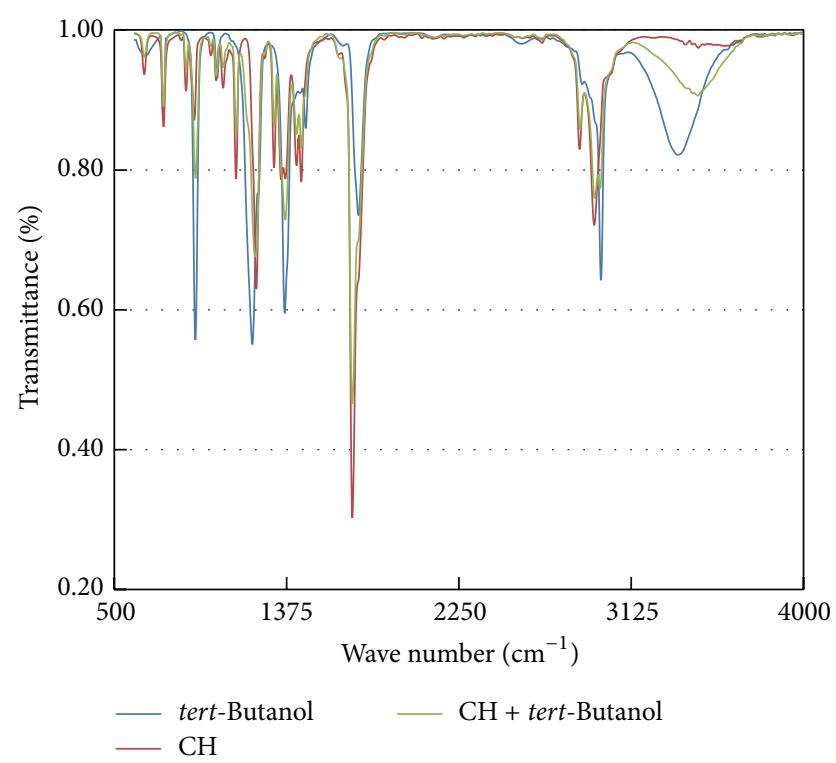

FIGURE 10: Fourier transform infrared spectra of pure cyclohexanone (red), cyclohexanone and tert-butanol in the ratio 5:5 (green), and pure tert-butanol (blue).

alkyne $\mathrm{C} \equiv \mathrm{C}$ stretch) will show little or no absorption for this vibration. In the present FT-IR spectra liquid mixture shows very small variations in the intensity of the respective bonds, that is, dipole moment, and hence it supports that weak interactions take place between the components of liquid molecules.

Theoretical evaluation of ultrasonic speed in binary liquid mixtures and its correlation to study molecular interaction has been successfully done in recent years. Ultrasonic speeds in liquid mixtures have been calculated and compared with
TABLE 5: Partial molar volumes $\left(\bar{V}_{m, 1}^{\infty}, \bar{V}_{m, 2}^{\infty}\right)$ and excess partial molar volumes $\left(\bar{V}_{m, 1}^{E, \infty}, \bar{V}_{m, 2}^{E, \infty}\right)$ of the components at infinite dilution for all the systems at $308.15 \mathrm{~K}$.

\begin{tabular}{lcccc}
\hline System & $\bar{V}_{m, 1}^{\infty}$ & $\begin{array}{c}\bar{V}_{m, 2}^{\infty} \\
/\left(10^{-5} \mathrm{~m}^{3} \mathrm{~mol}^{-1}\right)\end{array}$ & $\bar{V}_{m, 1}^{E, \infty}$ & $\bar{V}_{m, 2}^{E, \infty}$ \\
\hline $\mathrm{CH}+$ n-butanol & 25.519 & 43.758 & 18.696 & 36.548 \\
$\mathrm{CH}+$ sec-butanol & 25.561 & 50.9205 & 19.253 & 42.933 \\
$\mathrm{CH}+$ tert-butanol & 30.034 & 55.000 & 23.211 & 47.790 \\
\hline
\end{tabular}

experimental values using various theories. Such an evaluation offers a simple method to investigate molecular interactions besides verifying the applicability of various theories to liquid mixtures.

Nomoto [24] established the following relation for sound speed $\left(U_{N}\right)$ based on the assumption of the linearity of the molecular sound speed and the additivity of molar volume:

$$
U_{N}=\left\{\frac{\left(\sum x_{i} R_{i}\right)}{\left(\sum x_{i} V_{i}\right)}\right\}^{3},
$$

where $R_{i}$ is molar sound speed and $V_{i}$ is molar volume.

van Dael and Vangeel [25] obtained the ideal mixture relation

$$
\sum\left(\frac{x_{i} M_{i}}{u_{i}^{2}}\right)=\left\{\frac{1}{\sum x_{i} M_{i}}\right\}\left\{\frac{1}{U_{V}}\right\}^{2}
$$

Baluja and Parsania [26] have given impedance relation on the basis of force of resistance for sound speed by the interacting molecules

$$
U_{\text {imp }}=\frac{\sum x_{i} Z_{i}}{\sum x_{i} \rho_{i}}
$$

Rao's (specific sound speed) [27] relation is given by

$$
U_{R}=\left(\sum x_{i} r_{i} \rho\right)^{3},
$$

where $r_{i}=u_{i}^{1 / 3} / \rho_{i}$ is Rao's specific sound speed of $i$ th component of the mixture.

Percentage deviation in ultrasonic speed is given by

$$
\% \Delta u=100 *\left[1-\frac{U_{\mathrm{cal}}}{u_{\mathrm{exp} t}}\right] \text {. }
$$

Table 6 shows the values of ultrasonic speed computed by various theories along with their percentage error for all the systems. The variations between the evaluated and experimental values may be due to interactions occurring between the hetero molecules of the binaries. From the observed values of all three systems, there is a good agreement between theoretical and experimental values through van Deal and Vangeel relation. It can be seen from Table 6 that the theoretical values of ultrasonic speed calculated by using various theories show deviation from experimental values. The limitations and approximation incorporated in these theories 
TABLE 6: Theoretical values of ultrasonic speed from various equations and percentage error with mole fraction $x_{1}$ of $\mathrm{CH}$ for all binary systems at $308.15 \mathrm{~K}$.

\begin{tabular}{|c|c|c|c|c|c|c|c|c|}
\hline$x_{1}$ & $U_{N}$ & $U_{V}$ & $U_{\text {Imp }}$ & $U_{R}$ & $\% U_{N}$ & $\% U_{V}$ & $\% U_{\text {Imp }}$ & $\% U_{R}$ \\
\hline \multicolumn{9}{|c|}{$\mathrm{CH}+n$-butanol } \\
\hline 1.0000 & 1362.00 & 1362.00 & 1362.00 & 1362.00 & 0.00 & 0.00 & 0.00 & 0.00 \\
\hline 0.9121 & 1350.01 & 1345.47 & 1350.43 & 1298.06 & 1.43 & 1.09 & 1.46 & 2.48 \\
\hline 0.8854 & 1346.32 & 1340.60 & 1346.87 & 1283.17 & 1.77 & 1.33 & 1.81 & 3.01 \\
\hline 0.7211 & 1323.09 & 1311.99 & 1324.27 & 1221.96 & 3.05 & 2.18 & 3.14 & 4.83 \\
\hline 0.6687 & 1315.49 & 1303.34 & 1316.81 & 1209.73 & 3.22 & 2.27 & 3.32 & 5.08 \\
\hline 0.5232 & 1293.86 & 1280.42 & 1295.42 & 1185.02 & 3.33 & 2.26 & 3.46 & 5.36 \\
\hline 0.4752 & 1286.56 & 1273.19 & 1288.14 & 1178.71 & 3.17 & 2.10 & 3.30 & 5.48 \\
\hline 0.3231 & 1262.83 & 1251.29 & 1264.29 & 1163.93 & 2.61 & 1.68 & 2.73 & 5.42 \\
\hline 0.2112 & 1244.78 & 1236.09 & 1245.94 & 1161.66 & 1.96 & 1.25 & 2.05 & 4.85 \\
\hline 0.1313 & 1231.58 & 1225.67 & 1232.39 & 1168.83 & 1.35 & 0.86 & 1.42 & 3.82 \\
\hline 0.0000 & 1209.30 & 1209.30 & 1209.30 & 1209.30 & 0.00 & 0.00 & 0.00 & 0.00 \\
\hline \multicolumn{9}{|c|}{$\mathrm{CH}+$ sec-butanol } \\
\hline 1.0000 & 1362.00 & 1362.00 & 1362.00 & 1362.00 & 0.00 & 0.00 & 0.00 & 0.00 \\
\hline 0.9212 & 1348.36 & 1344.12 & 1349.36 & 1284.64 & 1.44 & 1.12 & 1.52 & 3.35 \\
\hline 0.8867 & 1342.34 & 1336.50 & 1343.75 & 1258.30 & 1.98 & 1.53 & 2.08 & 4.41 \\
\hline 0.7121 & 1311.30 & 1299.73 & 1314.35 & 1172.55 & 3.82 & 2.91 & 4.06 & 7.16 \\
\hline 0.6786 & 1305.24 & 1293.00 & 1308.52 & 1162.63 & 4.02 & 3.04 & 4.28 & 7.35 \\
\hline 0.5123 & 1274.65 & 1260.97 & 1278.60 & 1131.58 & 4.33 & 3.21 & 4.65 & 7.38 \\
\hline 0.4688 & 1266.50 & 1252.96 & 1270.49 & 1127.05 & 4.22 & 3.10 & 4.55 & 7.26 \\
\hline 0.3121 & 1236.66 & 1225.24 & 1240.27 & 1120.04 & 3.38 & 2.43 & 3.69 & 6.37 \\
\hline 0.2797 & 1230.39 & 1219.72 & 1233.81 & 1120.51 & 3.13 & 2.23 & 3.41 & 6.08 \\
\hline 0.1112 & 1197.22 & 1192.10 & 1199.01 & 1138.85 & 1.41 & 0.98 & 1.56 & 3.53 \\
\hline 0.0000 & 1174.80 & 1174.80 & 1174.80 & 1174.80 & 0.00 & 0.00 & 0.00 & 0.00 \\
\hline \multicolumn{9}{|c|}{$\mathrm{CH}+$ tert-butanol } \\
\hline 1.0000 & 1362.00 & 1362.00 & 1362.00 & 1362.00 & 0.00 & 0.00 & 0.00 & 0.00 \\
\hline 0.9221 & 1340.13 & 1335.38 & 1344.13 & 1269.23 & 2.09 & 1.73 & 2.40 & 3.31 \\
\hline 0.8895 & 1330.99 & 1324.56 & 1336.51 & 1236.00 & 2.83 & 2.33 & 3.25 & 4.51 \\
\hline 0.7012 & 1278.40 & 1265.44 & 1290.65 & 1095.88 & 5.61 & 4.54 & 6.63 & 9.46 \\
\hline 0.6814 & 1272.89 & 1259.53 & 1285.64 & 1085.50 & 5.78 & 4.67 & 6.84 & 9.80 \\
\hline 0.5112 & 1225.70 & 1211.04 & 1240.87 & 1023.59 & 6.33 & 5.06 & 7.64 & 11.21 \\
\hline 0.4777 & 1216.45 & 1201.95 & 1231.70 & 1016.61 & 6.27 & 5.01 & 7.61 & 11.19 \\
\hline 0.3321 & 1176.38 & 1164.00 & 1190.36 & 1004.06 & 5.48 & 4.37 & 6.74 & 9.97 \\
\hline 0.2635 & 1157.60 & 1146.96 & 1170.00 & 1007.94 & 4.80 & 3.84 & 5.92 & 8.75 \\
\hline 0.1323 & 1121.83 & 1115.75 & 1129.39 & 1033.39 & 2.89 & 2.33 & 3.58 & 5.23 \\
\hline 0.0000 & 1086.00 & 1086.00 & 1086.00 & 1086.00 & 0.00 & 0.00 & 0.00 & 0.00 \\
\hline
\end{tabular}

are responsible for the deviations of theoretical values from experimental values. Nomoto's theory proposes that the volume does not change upon mixing. Therefore, no interaction between the components of liquid mixtures has been taken into account. Similarly, the assumption for the formation of ideal mixing relation is that the ratios of specific heats of ideal mixtures and the volumes are also equal. Again no molecular interactions are taken into account. But upon mixing, interactions between the molecules occur because of the presence of various types of forces such as dispersion forces, charge transfer, and hydrogen bonding dipole-dipole and dipoleinduced dipole interactions. Thus, the observed deviation of theoretical values of speed from the experimental values shows that the molecular interactions are taking place between the $\mathrm{CH}$ and isomers of butanol molecules. The deviations of experimental values and values calculated from impedance relation and Rao's relation imply nonadditivity of acoustic impedance and Rao's speed in the liquid mixtures. Among all the empirical theories van Dael and Vangeels relation gives better estimate of experimental values of sound speed in all the systems. In the present binary systems, the difference between experimental and theoretical speeds is greater where the mole fraction of $\mathrm{CH}$ varies in the region 0.3 to 0.6 . Hence it can be qualitatively inferred that the strength of interaction in the binary mixtures is more in this range of composition of $\mathrm{CH}$ with isomers of butanol liquid system. 


\section{Conclusion}

(i) Ultrasonic speeds, $u$, and densities, $\rho$, of mixtures of cyclohexanone with $n$-butanol or sec-butanol or tertbutanol over the entire composition range have been measured at $T=308.15 \mathrm{~K}$.

(ii) The values of $V_{m}^{E}, \Delta k_{s}, L_{f}^{E}, z^{E}$, and $\Delta u$ are calculated from experimental data of density and ultrasonic speed. The excess and deviation properties have been fitted to Redlich-Kister type polynomial and corresponding standard deviations have been evaluated. The observed positive values of $V_{m}^{E}, \Delta k_{s}$, and $L_{f}^{E}$ and negative values of $z^{E}, \Delta u$ for all the liquid mixtures studied clearly indicate the presence of weak interactions such as rupturing of hydrogen bond or reduction in H-bond strength of butanol or breaking of the structure of one or both of the components in a solution.

(iii) The deviation/excess properties have been fitted to Redlich-Kister type polynomial and the corresponding standard deviations have been calculated.

(iv) The calculated values of partial molar volumes have also been examined. The observed higher partial molar volumes in the liquid mixture when compared to the respective molar volumes of pure components indicate weak interactions present in the systems.

(v) The strength of interaction in the mixtures follows the order $\mathrm{CH}+$, tert-butanol > sec-butanol >n-butanol.

(vi) FT-IR spectra for the present binary mixture also support the conclusions drawn from the $V_{m}^{E}, L_{f}^{E}, \Delta k_{s}$, $\Delta u$, and $z^{E}$.

(vii) Further theoretical values of sound speed in the mixtures have been evaluated using various theories and have been compared with experimental sound speeds to verify the applicability of such theories to the systems studied.

\section{Conflict of Interests}

The authors declare that there is no conflict of interests regarding the publication of this paper.

\section{Acknowledgment}

One of the authors, Sk. Md Nayeem, is thankful to UGC, New Delhi, Government of India, for the financial grants towards MRP (MRP-4671/14C (SERO-UGC)).

\section{References}

[1] T. B. Thoe, D. K. Aspinwall, and M. L. H. Wise, "Review on ultrasonic machining," International Journal of Machine Tools and Manufacture, vol. 38, no. 4, pp. 239-255, 1998.

[2] G. Thomas, Chemistry for Pharmacy and the Life Sciences, Prentice Hall, London, UK, 1996.
[3] A. M. Ababneh, C. C. Large, and S. Georghiou, "Solvation of nucleosides in aqueous mixtures of organic solvents: relevance to dna open basepairs," Biophysical Journal, vol. 85, no. 2, pp. 1111-1127, 2003.

[4] R. E. Treybal, Mass Transfer Operations, McGraw Hill, Singapore, 3rd edition, 1981.

[5] P. M. Krishna, B. R. Kumar, B. Sathyanarayana, K. S. Kumar, and N. Satyanarayana, "Densities and speeds of sound for binary liquid mixtures of thiolane-1,1-dioxide with butanone, pentan2-one, pentan-3-one, and 4-methyl-pentan-2-one at $T=(303.15$ or 308.15 or 313.15) K," Journal of Chemical and Engineering Data, vol. 54, no. 6, pp. 1947-1950, 2009.

[6] P. Gnana Kumari, P. Venkatesu, M. V. Prabhakara Rao, M.-J. Lee, and H.-M. Lin, "Excess molar volumes and ultrasonic studies of $N$-methyl-2-pyrrolidone with ketones at $T=303.15 \mathrm{~K}$," The Journal of Chemical Thermodynamics, vol. 41, no. 5, pp. 586-590, 2009.

[7] M. Sreenivasulu and P. R. Naidu, "Excess volumes and adiabatic compressibility of binary mixtures of butyl amine and cyclic ketones," Australian Journal of Chemistry, vol. 32, no. 8, pp. 1649-1652, 1979.

[8] K. Rajagopal and S. Chenthilnath, "Excess thermodynamic studies of binary liquid mixtures of 2-methyl-2-propanol with ketones," Indian Journal of Pure \& Applied Physics, vol. 48, no. 5, pp. 326-333, 2010.

[9] R. K. Bachu, M. K. Patwari, S. Boodida, and S. Nallani, "Volumetric and transport properties of binary liquid mixtures of aliphatic ketones with phenylacetonitrile at $T=308.15 \mathrm{~K}$," Journal of Chemical \& Engineering Data, vol. 53, no. 10, pp. 24032407, 2008.

[10] N. G. Tsierkezos, I. E. Molinou, and A. C. Filippou, "Thermodynamic properties of binary mixtures of cyclohexanone with $n$-alkanols $\left(\mathrm{C}_{1}-\mathrm{C}_{5}\right)$ at $293.15 \mathrm{~K}$," Journal of Solution Chemistry, vol. 34, no. 12, pp. 1371-1386, 2005.

[11] M. Sri Lakshmi, R. R. Raju, C. Rambabu, G. V. R. Rao, and K. Narendra, "Study of molecular interactions in binary liquid mixtures containing higher alcohols at different temperatures," Research \& Reviews: Journal of Chemistry, vol. 2, no. 1, pp. 12-24, 2013.

[12] A. I. Vogel, Text Book of Practical Organic Chemistry, Longman, London, UK, 5th edition, 1989.

[13] J. A. Riddick, W. Bunger, and T. K. Sakano, Techniques of Chemistry, Organic Solvents, Physical Properties and Methods of Purification, Wiley Interscience, New York, NY, USA, 4th edition, 1987.

[14] R. K. Bachu and M. K. Patwari, "Densities, viscosities and speed of sound of binary mixtures of phenylacetonitrile with some aliphatic alcohols at $308.15 \mathrm{~K}$," Indian Journal of Chemistry A, vol. 47, no. 7, pp. 1026-1031, 2008.

[15] H. C. Parker and E. W. Parker, "Densities of certain aqueous potassium chloride solutions as determined with a new pyknometer," Journal of Physical Chemistry, vol. 29, pp. 130-137, 1925.

[16] O. Redlich and A. T. Kister, "Algebraic representation of thermodynamic properties and the classification solutions," Industrial and Engineering Chemistry, vol. 40, no. 2, pp. 345348, 1948.

[17] R. Vijaya Kumar, S. Viswanathan, and M. Anand Rao, "Excess volumes, speeds of sound, and isentropic compressibilities of 2-propyn-1-ol + 1,2-dichloroethane, +1,1,1-trichloroe thane, $+1,1,2,2$-tetrachloroethane, and +trichloroethylene at $303.15 \mathrm{~K}$, 
Journal of Chemical and Engineering Data, vol. 41, no. 4, pp. 755757, 1996.

[18] J. S. Matos and J. L. Trenzado, "Volumetric properties and viscosities of the methyl butanoate+n-heptane+n-octane ternary system and its binary constitutions in the temperature range from 283.15K to 313.15K," Fluid Phase Equilibria, vol. 186, pp. 207-234, 2001.

[19] O. Kiyohara and G. C. Benson, "Ultrasonic speeds and isentropic compressibilities of $n$-alkanol $+n$-heptane mixtures at 298.15 K," The Journal of Chemical Thermodynamics, vol. 11, no. 9, pp. 861-873, 1979.

[20] R. J. Fort and W. R. Moore, "Adiabatic compressibilities of binary liquid mixtures," Transactions of the Faraday Society, vol. 61, pp. 2102-2111, 1965.

[21] A. Ali, A. K. Nain, V. K. Sharma, and S. Ahmed, "Ultrasonic studies in binary liquid mixtures," Indian Journal of Physics B, vol. 75, no. 6, pp. 519-525, 2001.

[22] M. Gowrisankar, S. Sivarambabu, P. Venkateswarlu, and K. S. Kumar, "Excess volumes, speeds of sound, isentropic compressibilities and viscosities of binary mixtures of $N$-ethyl aniline with some aromatic ketones at $303.15 \mathrm{~K}$," Bulletin of the Korean Chemical Society, vol. 33, no. 5, pp. 1686-1692, 2012.

[23] T. Karunakar and C. H. Srinivas, "Thermo acoustic and infrared study of molecular interactions in binary mixture aniline+1butanol," Research \& Reviews: Journal of Pure and Applied Physics, vol. 1, no. 1, pp. 5-10, 2013.

[24] O. Nomoto, "Empirical formula for sound velocity in liquid mixtures," Journal of the Physical Society of Japan, vol. 13, no. 12, pp. 1528-1532, 1958.

[25] W. van Dael, Thermodynamic Properties and Velocity of Sound, Butterworth, London, UK, 1975.

[26] S. Baluja and P. H. Parsania, "Acoustical properties of 3- $\alpha$-furyl acrylic acid in protic and aprotic solvents," Asian Journal of Chemistry, vol. 7, pp. 417-423, 1995.

[27] K. Sreekanth, D. S. Kumar, M. Kondaiah, and D. Krishna Rao, "Study of molecular interactions in the mixtures of secondary alcohols with equimolar mixture of ethanol + formamide from acoustic and thermodynamic parameters," Journal of Chemical and Pharmaceutical Research, vol. 3, no. 4, pp. 29-41, 2011. 

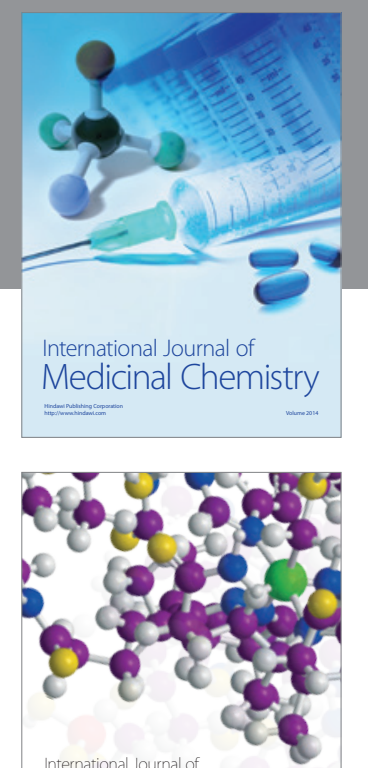

\section{Carbohydrate} Chemistry

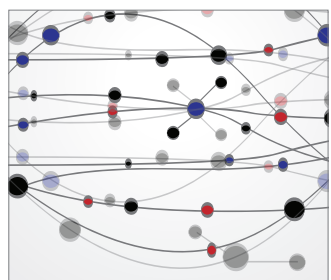

The Scientific World Journal
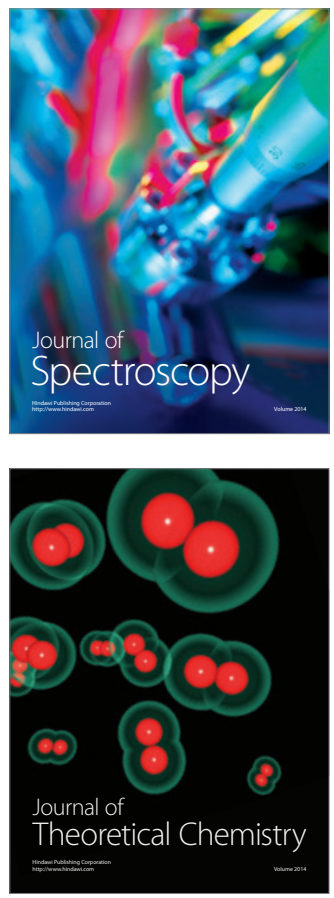
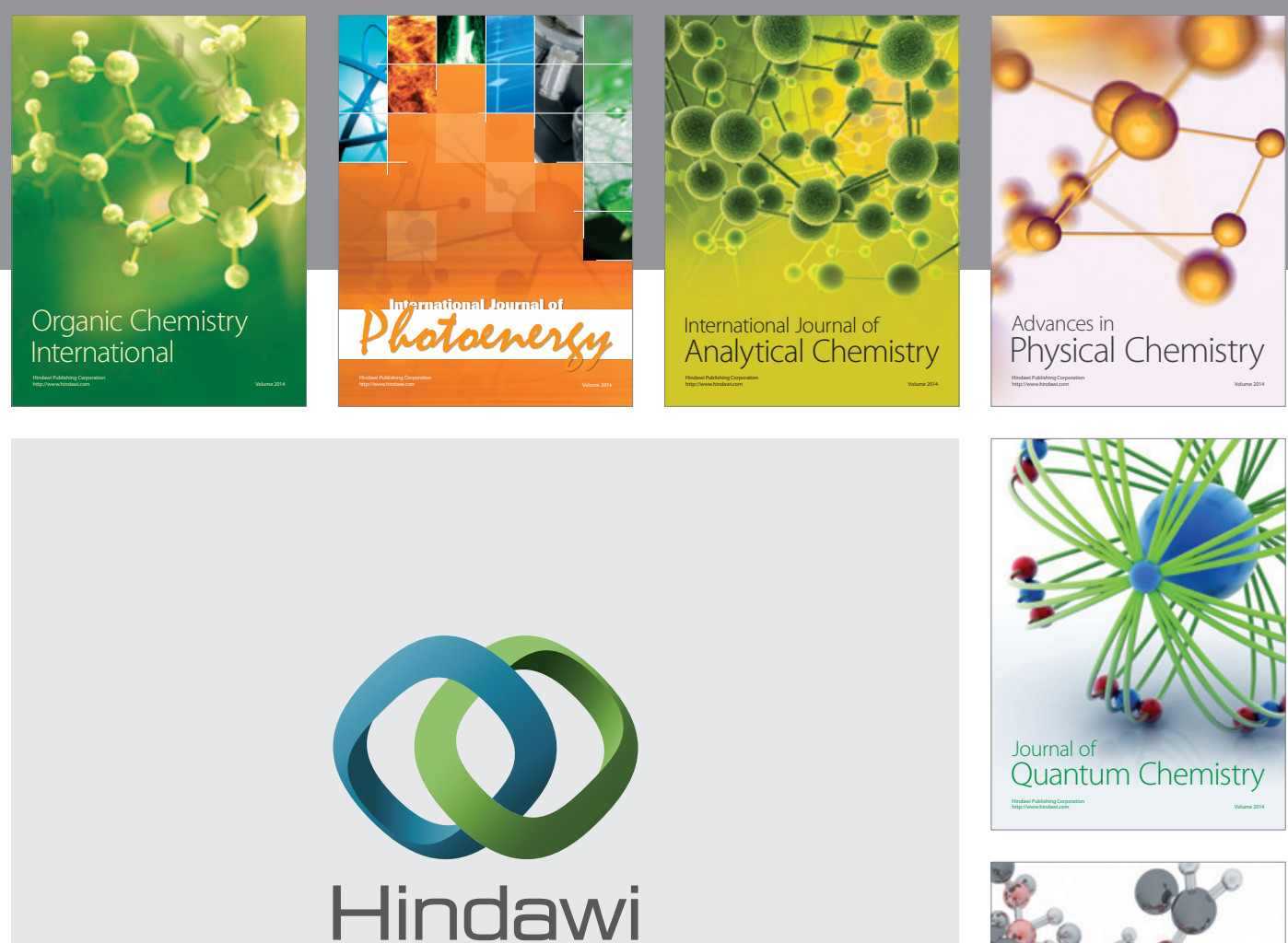

Submit your manuscripts at

http://www.hindawi.com

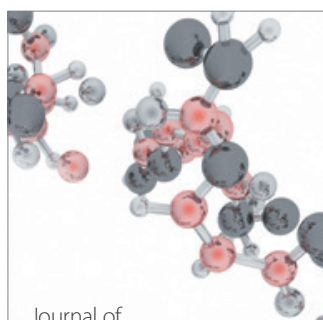

Analytical Methods

in Chemistry

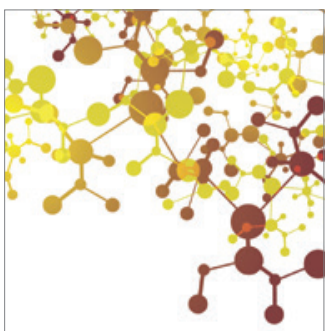

Journal of

Applied Chemistry

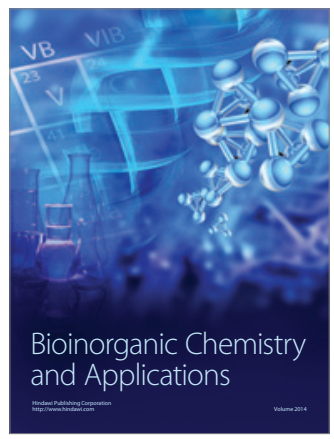

Inorganic Chemistry
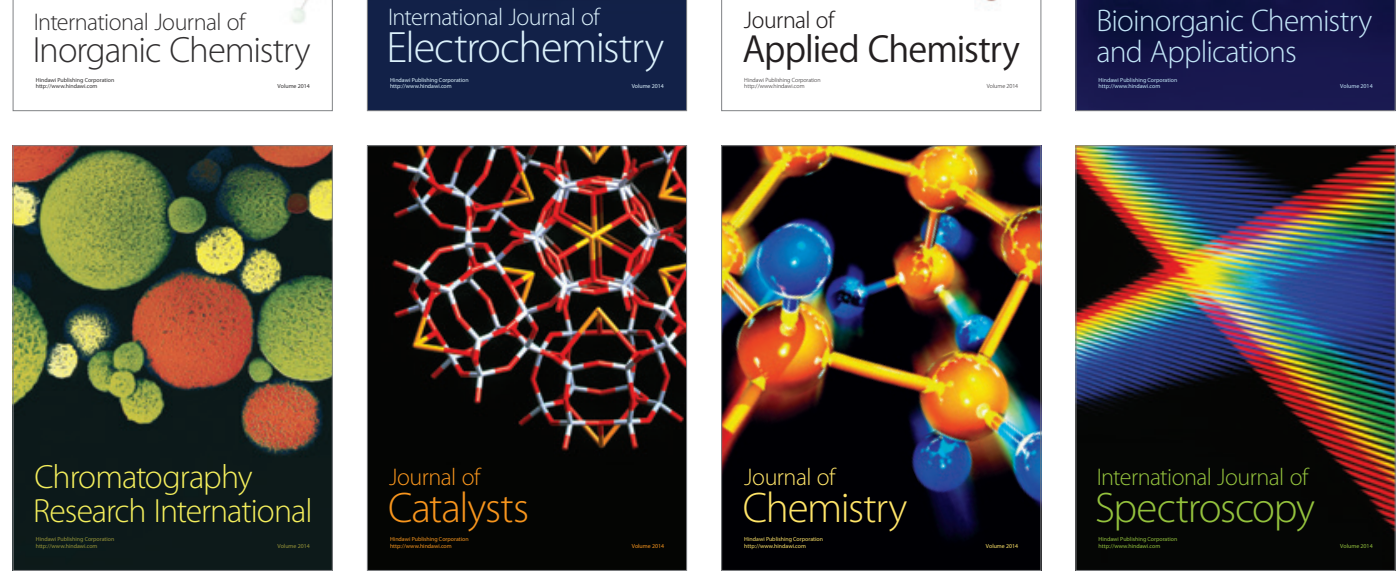